\author{
Dreaming Other Worlds: \\ Commodity Culture, Mass Desire, and the Ideology of Inception \\ Martin Danyluk \\ Department of Geography \\ University of Toronto \\ 100 St. George Street, Room 5047 \\ Toronto, Ontario M5S 3G3 \\ Canada
}

\begin{abstract}
This essay engages in a critical reading of the 2010 science-fiction film Inception in order to advance two theses about contemporary mass culture. First, mainstream cultural products contain within them certain utopian moments. Yet while these works may offer glimpses of a world radically transformed in certain respects, this transcendent impulse rarely extends to their depiction of social relations. In fact, such objects can be effective in consolidating dominant ideologies and naturalizing the existing political-economic order, because their sharp break from scientific or metaphysical realities may serve to conceal their symptomatic silences on matters of social organization. Second, this tension internal to commercial culture poses an opportunity for political intervention. The mass cultural product, insofar as it must appeal to broadly felt desires, frequently makes a utopian or transformative promise that cannot be realized by the commodity itself. A culturally attuned Left could highlight this inadequacy by reappropriating mainstream cultural symbols in order to draw broader attention to struggles for social transformation.
\end{abstract}

Keywords: ideology, utopia, mass culture 


\section{The Power of Dreams}

In March 2011, Chinese authorities issued a stern denunciation of a popular style of TV dramas that feature time travel and supernatural elements. In a statement that many read as tantamount to a prohibition, China's State Administration of Radio, Film and Television (2011) said that such programs "tend toward ambiguous values" and suffer from frivolous plots that distort history. Speaking to demonstrators at Occupy Wall Street later that year, Slavoj Žižek offered an unlikely interpretation of the ban.

This is a good sign for China. It means people still dream about alternatives, so you have to prohibit this dreaming. Here we don't need a prohibition, because the ruling history has even oppressed our capacity to dream. (Žižek 2011)

For Žižek, the absence of overt censorship in the West suggests that the grip of ideology is sufficiently powerful there to prevent visions of alternative worlds from being taken seriously in the first place. "We 'feel free," he explains, "because we lack the very language to articulate our unfreedom" (Žižek 2002, 2).

What is contemporary Western culture capable of dreaming? One answer is found in the cinema. Today's moviegoers are exposed to aliens and predators, transformers and terminators, spider-men and iron men, Jurassic parks and deep impacts, but many have never seen a world free of the shackles of racism, patriarchy, or wage labor. While Hollywood presents bold new visions related to science and technology, on questions of politics and society it cleaves dismally to the status quo. If, as the saying goes, it is now easier to imagine the end of the world than to imagine the end of capitalism, then mainstream cinema is at once a source and a symptom of this ideological condition. And of course, such cultural patterns map closely onto political dynamics. Fifty years ago Herbert Marcuse $(1964,19)$ inveighed against "the closing of the political universe"; today the poverty of imagination in the West is such that even many nominally leftist parties offer no alternative to austerity, antiunion politics, and the extension of market relations into ever-broader areas of social life. The horizons of our collective dreams, it would seem, reach further in some directions than in others.

It is precisely the notion of shared dreaming that forms the central conceit of the 2010 science-fiction film Inception, written and directed by Christopher Nolan. The movie's protagonists venture into the realm of human dreams, where together they create alternative worlds bounded only by their collective imagination. Yet through the fantasies it depicts, Inception implicitly reveals the ideological limits of the social order that produced it. The film explores radical alternatives in the domains of space, time, and metaphysics, but this critical impulse does not extend to the realm of social relations. For all the ambitious questions it poses, the movie takes the political and economic organization of early twenty-first-century capitalism as a given.

This essay stages a critical reading of Inception in order to advance two theses on contemporary mass culture in general. First, mainstream cultural products contain within them certain utopian moments, glimpses of a radically transformed world. Yet while these works may break sharply from reality in certain respects, they rarely offer a transformative portrayal of social arrangements. In fact, such objects can be effective in consolidating dominant ideologies and 
naturalizing the given social order, because their radical metaphysical or scientific content may serve to conceal their profound silence on questions of political and economic organization. Inception is an exemplary work in which to observe the interplay between the said and the unsaid, the dialectics of possibility and impossibility. The film's spectacular suspension of natural laws works to obscure its tacit endorsement of hegemonic social meanings and values.

However-and this is the second point-this tension internal to commercial culture presents an opportunity for political intervention. The mass cultural commodity, if it is to fulfill its function as such, must appeal to broadly felt wants and needs, and this task may be performed by utopian content that plays to people's desire for substantive change. Yet in doing so, the work necessarily institutes a lack-a promise of radical transformation that cannot be realized by the commodity itself. Through the device of shared dreaming, Inception exhorts audiences to consider their own collective capacity for imagining and building a radically different world. Thus, even as the film reifies the social order from which it springs, it also offers a partialalbeit inadequate-resolution to viewers' desire for things to be otherwise. While it is tempting to denounce such works as conservative, the more radical critique is the one that engages the commodity's contradictions directly, highlighting its inability to fulfill the desire it promises to fulfill (Thompson 2010). A culturally attuned Left could take up this task by reappropriating mainstream cultural symbols in its own movements for social transformation.

\section{Ideology in Mass Culture}

What is the role of mainstream culture in working out and patrolling the perceived boundary between the possible and the impossible? One strand of Marxian literary theory, beginning with the work of Pierre Macherey in the 1960s, focuses on the silences of cultural objects as important sites for the operation of ideology. Macherey (1978) argues that literary works disclose their ideological character by virtue of what they do not, and cannot, say. According to this view, the narrative structures of texts, by way of such constitutive absences, "conceal the ideological standpoints from which they emerge and to which they contribute" (Goonewardena 2004, 684). Crucially, these silences are not arbitrary: the text is ideologically forbidden from uttering certain statements.

This approach points to a particular role for literary criticism. For Macherey, it is the dissonance between the spoken and the unspoken that reveals most about the work. A "symptomatic" reading of the text, as in the Freudian theory of the unconscious, permits the critic to uncover the absences and contradictions within it. The task of criticism here is not to fill in the gaps, which would amount to an interminable exercise in saying the unsaid, but to inquire into the internal relation between the explicit and the implicit in order to explain the text's silences in their ideological necessity.

"Ideology" is used here in the sense proposed by Althusser (2001, 109): "the imaginary relationships of individuals to their real conditions of existence." Ideologies, for Althusser, are the everyday vocabularies whereby people make sense, however incompletely or incoherently,

of the complex reality in which they make their lives. They are the interpretations in thought- 
Jameson $(1984,90)$ likens them to a "cognitive map" - through which individuals represent to themselves their own location within an unrepresentable social totality. Importantly, ideologies are not mere delusions: they represent real social relations and processes, and if they are to endure, they must help individuals navigate and make sense of those structures. It follows that ideologies cannot be straightforwardly "transmitted" by way of newspapers or feature films; they must be deduced and validated in daily practice (Fields 1990).

In this respect, cultural production can be theorized as a process of mediation, an active transcoding of ideological material that admits of both continuity and difference. Cultural activity may reinforce certain values and beliefs by reinstating particular silences, but it also involves an element of refraction or displacement through which prevailing meanings may be destabilized or new ones generated. This necessary dissonance between the cultural object and the ideological complex from which it springs affords the work a certain liberatory potential. As Eagleton (2006, 89-90) explains,

The literary text, far from constituting some unified plenitude of meaning, bears inscribed within it the marks of certain determinate absences which twist its various significations into conflict and contradiction.... In so putting ideology to work, the text begins to illuminate the absences which are the foundation of its articulate discourse.

In other words, by internalizing and bringing to light the ideological antagonisms of its own conditions of production, the work contains the possibility of altering or refusing those conditions. It follows that mainstream culture, even as it serves to consolidate dominant social meanings and expectations, also incorporates a "transcendent" or "critical" impulse, however faint (Jameson 1979, 144). We can therefore extend the procedure of symptomatic reading to examine the dialectical relation between the work's determinate silences and its utopian moments. It is to this task, and to Inception, that I now turn.

\section{Seduction and Heartbreak}

When it was released in the summer of 2010, Inception dazzled audiences, quickly earning a spot among the highest-grossing films of all time. The movie takes viewers inside the vivid and surreal world of human dreams-a universe that, we are told, is governed by a fundamentally different metaphysical order. Leonardo DiCaprio plays Dom Cobb, a professional "dream thief" who uses declassified military technology to enter the subconscious minds of his sleeping targets and extract valuable information for corporate clients. ${ }^{1}$ The key to these espionage operations is a technique called shared dreaming. Cobb's extraction team and the target of the heist are sedated and tethered together intravenously; one individual constructs the dreamworld while it is populated with people and objects from the subconscious of another. As Cobb explains, this dream-sharing procedure allows the extractors to call forth the intelligence they are trying to steal by creating some secure environment, like a vault: "The mind automatically fills it with information it's trying to protect."

We learn that Cobb is a fugitive, wanted for murder in the United States and unable to see his children. But a powerful businessman, Mr. Saito, offers him a chance to get his old life back 
by performing a supposedly impossible maneuver called inception. Instead of extracting information, this task involves planting an idea in a target's mind that will bear fruit in the waking world. Saito wants to persuade Robert Fischer, the heir to a major energy conglomerate, to break up the corporate empire of his dying father; this will keep Fischer from acquiring monopolistic control over the world's energy supply while also ensuring that Saito himself remains a viable competitor. For the idea to stick, though, it must appear to come from Fischer himself. If Cobb can carry off the inception, Saito will use his influence to clear the charges against Cobb, allowing him to reenter the United States and reunite with his children.

The heist is scheduled for a long-haul flight over the Pacific. Cobb and his team sedate Fischer and enter a dream with him. To keep him from discovering that they have infiltrated his mind, they conspire to plant the idea deep within his subconscious, where the power of raw emotion will lead it to take root as if it were an original creation. The team devises an elaborate scheme involving a dream within a dream within a dream. Much of Inception's 148-minute running time is given over to explaining the labyrinthine system of rules that governs its dreamworld; viewers have struggled to decode the intricacies of these conventions (including procedures for waking up dreaming subjects and for determining whether one is in someone else's dream) and of the characters' movements between the various dream levels. The story is further complicated by the appearance of impersonators in dreams, by Cobb's own troubled history of experimentation with shared dreaming, by militarized "projections" who defend the mind of a trained subject against intruders, and by the danger of falling into an even deeper psychic state called limbo-a space of "raw, infinite subconscious."

Inception opened to mixed reviews, with the most influential critics expressing the deepest reservations. The movie's technical overindulgence and rule-bound script, many opined, precluded any serious exploration of the irrationality of the subconscious mind. Salon critic Andrew O'Hehir (2010) called the film "the most tight-assed vision of the innermost human psyche I've ever seen." But the public response told a different story. Inception grossed over $\$ 800$ million worldwide, surpassing box-office favorites like Spider-Man, E.T., and Star Wars, and inspired hundreds of fan sites and fierce online debates over its ambiguous conclusion.

Doing justice to such a work therefore means asking what enables it to resonate with the "structures of feeling" (Williams 1980,22) that inhabit mass consciousness in a particular historical moment. Audience reviews suggested the film captivated viewers in part because it afforded glimpses of worlds radically unlike our own. Comments like the following (from the Internet Movie Database) betrayed more than a hint of desire on the part of viewers to escape their own imperfect lives for Inception's spectacular dreamscape.

The only problem i had was that i didn't want the movie to [be] over, i just wanted to be a part of his dream world. (varuunchaudry, July 19, 2010)

Nolan is able to hypnotize the audience, and dispatch us into the dream world. . . It was implausible, and spellbinding to watch. (Jared Christenson, July 22, 2010) 
This is one of those movies that leaves you sitting in the theater after the credits not wanting to believe its over and that you now have to go on with your drab, boring life. (T Cady, September 29, 2012)

Others identified a slightly different current at work: a promise of freedom or self-realization, a possibility of taking charge of the conditions of one's own existence.

"Inception" has at its heart the ... idea that we are all masters of our own destiny: architects of our own dreams, if you will. We are only beholden to the thoughts, dreams, and accomplishments of others to the extent that we allow ourselves to be. (jim pyke, July 16, 2010)

Such remarks suggest that Inception secured its mass appeal by engaging a widely felt desire for things to be other than as they are-and, moreover, by disclosing to viewers their own latent capacity to transform the world.

Inception departs from everyday experience in at least three ways. First, its dreamscape is governed by an unfamiliar spatiotemporal framework, one that enables its inhabitants to express their creative powers in ways that modern society has rendered all but unthinkable. Time, we are told, passes more slowly in a dream. This proposition introduces the possibility of time elapsing at different rates for different subjects, as in Einstein's theory of relativity. Inception takes this principle further by nesting dreams within dreams, with each layer compounding the time-dilation effect. When we reach limbo, the deepest level of the human psyche, just a few minutes of slumber feels like decades for the dreamer. As Cobb explains, such temporal indeterminacy opens up a vast field of creative experimentation: "the chance to build cathedrals, entire cities-things that have never existed, things that couldn't exist in the real world." It also affords a window into a utopian future in which the tens of thousands of hours we currently spend working for someone else, in that capitalistic process of self-negation that Marx (1978) called "estranged" or "alienated" labor, have been reappropriated for free, self-directed activity.

The film offers a similarly novel conception of space, characterized by an intimate relation between the human mind and the built environment. Anything a dreamer can imagine can be brought to fruition, including such "paradoxical architecture" as the Penrose stairs made famous by M. C. Escher. Giant structures rise from the ground; mirrors dissolve into thin air. Freed of the rigid axioms of Euclidean geometry, spatiality becomes playful and enchantingand sometimes impossibly beautiful. In a scene that depicts Cobb teaching his young apprentice how to design the dreamworld, she lets her imagination take over, folding the streets of Paris in upon themselves like a book (fig. 1). In the capitalist core, where the power to transform the urban landscape has long been denied to the great majority, such moments evoke something of the revolutionary spirit of Henri Lefebvre's (1996) "right to the city": a claim to unmediated authorship over the production of space.

Inception's second break from everyday experience lies in its refusal of the solipsistic individualism that dominates contemporary political rationality. The neoliberal model of the atomistic individual_of independent mind and personally responsible for her own thoughts, behaviors, and life outcomes-is replaced here by a subjectivity that is constitutively relational. The physical universe experienced by Nolan's dreamers is not ontologically sealed but rather 
perforated by stimuli from the waking world and the dream levels above, which manifest as shifts in gravity, weather events, vibrations, sudden jolts, and music resonating throughout space. And because these dreams are shared, each person's lifeworld is produced by multiple individuals, bound together in a relation of intersubjective entanglement. The dreamscapes of Inception are therefore fundamentally social projects, co-constructed by a collectivity of subjects. This is equally true of our own world, of course, but we have been conditioned to see things otherwise.

Finally, the film invites viewers into a position of radical skepticism toward the authenticity of the given universe. Inception is centrally concerned to trouble the boundary between illusion and reality, and in doing so it invokes metaphysical questions that have widespread appeal. Its protagonists repeatedly struggle to discern reality from the simulacra of dreams, giving rise to a "general ontological indeterminacy" that casts doubt on the nature of the movie's entire universe (M. Fisher 2011, 37). These questions ultimately become self-referential, "turning back on the film itself" (D. Fisher 2010), when Inception's closing moments raise the possibility that the entire story has been a dream and that Cobb's fairy-tale ending is in fact a phantasm within which he has become trapped. The notion of shared dreaming, of course, is a fitting allegory of the modern cinema itself, and it is the film's final, reflexive gesture to this idea-the moment we realize we have opened ourselves to manipulation by entertaining a collective fantasy designed by the filmmaker himself-that constitutes its most intriguing moment. Inception's deep distrust of empirical reality unsettles the ontological status of the given world, creating a cognitive opening for its potential replacement by alternative worlds yet to be imagined.

Together, these three elements-a playful sense of space and time, a physical universe amenable to collective production, and a radical uncertainty about the nature of reality-make up a utopian current within Inception that helps account for its mass appeal. Yet despite its bold experimentation in the realm of metaphysics, the film is unable to imagine any other configuration of society. This dialectic of transcendence and reification becomes most evident with Inception's conclusion. Recall that Saito, the wealthy businessman, hired Cobb with the aim of ridding the global energy industry of a monopoly power. The presumably successful execution of the heist therefore represents the restoration of "healthy," competitive markets and the preservation of Saito's privileged position within that structure. In other words, the stakes in the film's heady, phantasmagorical journey into the nether reaches of the human mind boil down to a simple commercial transaction. Such are the symptomatic silences that haunt contemporary mass culture: of all the applications one could imagine for a device that let people enter each other's dreams, Hollywood can think of none more inspired than facilitating a corporate takeover. Here Nolan's poverty of imagination was met with ridicule from New York Times critic A. O. Scott (2010): "The pursuit of competitive advantage by well-dressed, emotionless men is hardly the stuff that dreams are made of."

Cobb, for his part, receives his wish of returning home to see his children. Inception's final minutes show him passing through US customs, having his passport stamped, presumably cleared of criminal wrongdoing. Resolution is associated with the restoration of full American 
citizenship and the realization of a host of bourgeois aspirations. It is a utopian moment in its own right, but it feels a shade too idyllic, too familiar, to be genuine: the protagonist withdraws to a private life with his family in his Pasadena bungalow, safe within the borders of the world's mightiest nation-state. The psychic and creative possibilities that Cobb once explored through shared dreaming are renounced as a distraction, a means to an end. Even the crucial ontological question that lends the film's closing scene a sense of unease-whether his happy ending is real or illusory-is one he no longer cares to answer.

For both Cobb and Saito, then, the ability to imagine and build extraordinary new worlds is reduced to an instrument for securing individual advantage within the world that already exists. The suggestion that reality is preferable to any alternative one could dream up-true, perhaps, if one happens to be a global energy baron or a white American patriarch granted early retirement-is bound to register as disingenuous to the millions of viewers who will exit the theater to a life over which they have limited control. Yet Inception effectively conceals its own symptomatic silences. The film's spectacular negation of the laws of physics and its radical doubt of reality serve as a powerful cover for its failure to extend that same critical impulse to social institutions and attitudes-competitive markets, American triumphalism, the private family - that are in fact highly transitory. Those values are instead presented as natural and eternal, presumed to outlast even fundamental disruptions to the fabric of the cosmos. In a way, then, the film furnishes us with tools for identifying its own inner contradictions-and, in turn, those of the social formation that produced it.

\section{Co-opting Mass Culture}

Cultural products that contain utopian elements may offer a partial resolution to audiences' longing for a different world, even as the specific social relations within which they were produced are rendered timeless, universal, or otherwise unworthy of discussion. Such works divert people's desire for control over their own lives away from questions of social transformation and into the less threatening realms of science and metaphysics. When the implausible (e.g., bending space and time) is presented as not only possible but also deeply gratifying, and when the actually achievable (e.g., eradicating homelessness) is portrayed as not only impossible but also unworthy of mention, the effect is to train the collective will on realizing the former and abandoning the latter. This ideological stance finds broad support in a social context in which immense resources and hopes are invested in the utopian promise of scientific and technological progress. Meanwhile, the repressive social arrangements that the work is unable to mention carry on unaltered, ossified in thought.

An opening emerges, however, from the fact that the vast majority of today's cultural artifacts are imprisoned in the commodity form. Through commodification, the cultural work is "reduced to a means for its own consumption" (Jameson 1979, 131). If the capital embodied within it is to realize a profit, it must resonate with the substantive hopes and dreams of large audiences, and one way to garner this mass appeal is by mobilizing utopian imagery. Consequently, many a cultural product makes a promise of transformation that cannot be realized by 
the commodity itself. So long as it appears impossible to actually construct a radically different world, the only way to prolong the pleasure afforded by Inception's oneiric universe is to watch the film over and over again.

The resulting sense of disenchantment presents an opportunity for political intervention. Corporate capital has for decades co-opted the signs and symbols of the Left-think of the use of protest songs in bank advertisements or the serial reproduction of Che Guevara's face on Tshirts-but nothing prevents radical movements from appropriating elements of mass culture in return (Thompson 2010). Indeed, thinkers and activists have long recognized how popular imagery can help struggles for social transformation find mainstream relevance. In recent years, the Guy Fawkes mask featured in V for Vendetta has become a fixture of political protests from Occupy to Idle No More, while scholars like bell hooks (1997), Judith Halberstam (2011), and Catherine P. Mulder (2013) have used popular films as pedagogical tools, highlighting the interplay of conservative and revolutionary content within them. Seizing the utopian potential of works like Inception means recognizing popular culture as more than an instrument of rulingclass indoctrination: we need to understand what enables certain products to forge strong affective bonds. The promise of this approach is rooted in the paradox that commercial culture must whet the desire of the masses but can never sate it.

\section{Acknowledgments}

Thanks to Kanishka Goonewardena, Elizabeth Lord, Tom Malleson, Jessica Nelligan, Max Ritts, Amanda Watson, and the members of two writing workshops for their generous assistance with this paper. 


\section{References}

Althusser, L. 2001. Lenin and philosophy, and other essays. New ed. Translated by B. Brewster. New York: Monthly Review Press.

Eagleton, T. 2006. Criticism and ideology: A study in Marxist literary theory. New ed. London: Verso.

Fields, B. J. 1990. Slavery, race and ideology in the United States of America. New Left Review, no. 181: 95-118.

Fisher, D. 2010. Review of Inception. Journal of Religion and Film 14 (1). http://www.unomaha.edu/jrf/Vol14no1/Reviews/Inception.html.

Fisher, M. 2011. The lost unconscious: Delusions and dreams in Inception. Film Quarterly 64 (3): 3745.

Goonewardena, K. 2004. Postcolonialism and diaspora: A contribution to the critique of nationalist ideology and historiography in the age of globalization and neoliberalism. University of Toronto Quarterly 73 (2): 657-90.

Halberstam, J. 2011. The queer art of failure. Durham, NC: Duke University Press.

Hooks, b. 1996. Reel to real: Race, sex, and class at the movies. New York: Routledge.

Jameson, F. 1979. Reification and utopia in mass culture. Social Text, no. 1: 130-48.

- 1984. Postmodernism, or the cultural logic of late capitalism. New Left Review, no. I/146: 5392.

Lefebvre, H. 1996. Writings on cities. Translated and edited by E. Kofman and E. Lebas. Malden, MA: Blackwell.

Macherey, P. 1978. A theory of literary production. Translated by G. Wall. London: Routledge and Kegan Paul.

Marcuse, H. 1964. One-dimensional man: Studies in the ideology of advanced industrial society. Boston: Beacon Press.

Marx, K. 1978. Economic and philosophic manuscripts of 1844. In The Marx-Engels reader, edited by R. C. Tucker, 2nd ed., 66-125. New York: W. W. Norton.

Mulder, C. P. 2013. It's the time of your life: Marxism in animated films. Rethinking Marxism: A Journal of Economics, Culture and Society 25 (2): 284-92.

O'Hehir, A. 2010. "Inception": A clunky, overblown disappointment. Salon, July 14.

Scott, A. O. 2010. This time the dream's on me. Review of Inception. New York Times, July 16, C1.

State Administration of Radio, Film, and Television (China). 2011. March 2011 notice by the Radio and Television Bureau announcing TV dramas filed nationwide [in Chinese]. March 31. http://www.sarft.gov.cn/articles/2011/03/31/20110331140820680073.html.

Thompson, A. K. 2010. Co-opting capitalism: Avatar and the thing itself. Upping the Anti, no. 10: 7796.

Williams, R. 1980. Problems in materialism and culture: Selected essays. London: Verso.

Žižek, S. 2002. Welcome to the desert of the real! Five essays on September 11 and related dates. London: Verso.

- 2011. Zizek joins Occupy Wall Street in New York-10/9/11. Filmed October 9. YouTube video, 14:56. Posted by “munderlarkst," October 13, 2011. https://www.youtube.com/watch?v=HdyMV1AKHGg. 
1. Despite its numerous allusions to psychoanalytic theory, Inception refers to the locus of dreams using the lay term "subconscious" rather than Freud's preferred "unconscious." I follow the film's usage here. 